\title{
THE GOOD AND BAD OF PRODUCT PROGRAM INNOVATIVENESS: EVIDENCE FROM BUYER AND SELLER COMPANIES
}

\author{
Ruth Maria Stock, Technische Universität Darmstadt, Germany \\ Nicolas Andy Zacharias, Technische Universität Darmstadt, Germany
}

\begin{abstract}
Innovations appear to play a key role in the endeavor to keep business-to-business (B2B) customers attracted, as they offer several advantages to B2B customers and help customers improving their own products. Despite the critical role of new products in creating strong B2B ties, half of all new products introduced never succeed but fail in the marketplace (Lynn et al. 1999; Morris et al. 2003). A possible reason for such failures may be errors in companies' valuation of customer responses to innovations, on which the success of innovations ultimately hinges (Hauser et al. 2006). Companies might focus only on positive customer responses toward innovativeness, but ignore potential negative customer responses to new products, such as customers turning away from a particular supplier (Athanassopoulos et al. 2001). As a consequence, companies need to understand both positive and negative customer responses to innovativeness.
\end{abstract}

Empirical research into customer responses to innovative products offers mixed findings (e.g., Henard and Szymanski 2001). Many studies report positive effects of innovativeness on customer-related outcomes, such as customer acceptance (e.g., Langerak et al. 2004), but others convey that innovativeness has negative effects (e.g., Atuahene-Gima 1996). From a conceptual point of view, innovativeness features distinct dimensions - such as product newness and meaningfulness - which may generate different customer responses. While product newness may provoke negative associations for customers, such as increased uncertainty (Schmidt and Calantone 1998), product meaningfulness appears to be associated with positive customer outcomes, such as better fulfillment of customer needs (Gatignon and Xuereb 1997). These findings reveal that both dimensions of innovativeness generate customer responses, but in different manners. A comprehensive understanding of customer-related outcomes of innovativeness requires an investigation of different dimensions of innovativeness in parallel (e.g., Hauser et al. 2006; Szymanski et al. 2007), which has been largely neglected by extant research so far.

Since understanding different customer responses to newness and meaningfulness would be of great interest to both academics and managers, this study introduces a multidimensional conceptualization of innovativeness at the program level, consisting of newness and meaningfulness as two particularly important but distinct dimensions of innovativeness. Building on information economics (e.g., Phlips 1988; Stigler 1961), we compare different customer responses toward the newness and meaningfulness dimensions of product program innovativeness in terms of customer loyalty. Our empirical results support the notion that the two dimensions of product program innovativeness are distinct and have varying effects. In addition, we also investigate contingencies that might alter the relationship between the different dimensions of product program innovativeness and customer loyalty.

Empirical support comes from a multi-industry sample with triadic data from 180 B2B companies and includes assessments from marketing and R\&D managers as well as customers. While the managers assessed company-related variables, customers provided information regarding their loyalty. The results of the regression analysis indicate a negative effect of product program newness on customer loyalty and a positive effect of product program meaningfulness. Regarding contingencies, a brand's close association with innovativeness reduces the negative effect of product newness, and integrating customers into the value-creating process fosters the loyalty effect of product meaningfulness. Thus, product program innovativeness itself offers a good and a bad side: a positive and a negative effect on customer loyalty.

Our research has several important implications. This study offers a potential explanation for the ambiguity created by equivocal empirical results regarding customer responses to innovativeness. Therefore, much of existing research that relies on uni-dimensional conceptualizations of innovativeness should be questioned and scholars should turn to measures capable of assessing multiple facets of the complex phenomenon (Sullivan and Ford 2010). By drawing on information economics, we provide insights into how customers derive their expected utility from the relationship with a specific company and how they react in terms of loyalty. We ascertain that more is not always better in terms of innovativeness - offering more innovations does not necessarily make customers loyal. Instead, we advise managers to mitigate the negative effects of product program newness, e.g., by associating their brands with innovativeness, and to strictly focus on the meaningfulness of new products.

References available upon request 